\title{
Measuring the Rate of Heat Loss Across Selected Building Materials
}

Genesis Zambrano

University of South Florida, gzambrano1@usf.edu

Advisors:

Arcadii Grinshpan, Mathematics and Statistics

Malik Arsalan Akram, Mathematics and Statistics

Elizabeth Zambrano, Independent Architect

Problem Suggested By: Elizabeth Zambrano

Field of Study for Problem Suggester: Independent Architect

Follow this and additional works at: https://digitalcommons.usf.edu/ujmm

Part of the Mathematics Commons

UJMM is an open access journal, free to authors and readers, and relies on your support:

Donate Now

\section{Recommended Citation}

Zambrano, Genesis (2020) "Measuring the Rate of Heat Loss Across Selected Building Materials,"

Undergraduate Journal of Mathematical Modeling: One + Two: Vol. 11: Iss. 1, Article 9.

DOI: https://doi.org/10.5038/2326-3652.11.1.4928

Available at: https://digitalcommons.usf.edu/ujmm/vol11/iss1/9 


\title{
Measuring the Rate of Heat Loss Across Selected Building Materials
}

\begin{abstract}
The rate of heat loss is analyzed for three materials: glass, brick and wood. To do this, the initial and final temperatures are set to $75^{\circ} \mathrm{F}$ and $100^{\circ} \mathrm{F}$, respectively, and the dimensions of each material are chosen to be $5 \mathrm{ft}$ by $5 \mathrm{ft}$ with a thickness of 2 inches. The objective of this paper is to see which material is best for insulating heat, thus enhancing the thermal performance of a building. Results from this study suggest that glass and brick have a higher rate of heat loss (high thermal conductance values and low thermal resistance values) compared to wood and are therefore poor insulators whereas wood, with a lower rate of heat loss (low thermal conductance value and a high thermal resistance value) serves as a better insulator.
\end{abstract}

Keywords

heat, rate of heat loss, thermal resistance, insulator, Fourier's Law

Creative Commons License

(c) (i) (8)

This work is licensed under a Creative Commons Attribution-Noncommercial-Share Alike 4.0 License. 


\section{PROBLEM STATEMENT}

The objective is to calculate how much heat is being lost through different building materials and to see how they compare.

\section{MOTIVATION}

During the building design process, architects consider many different factors that make a successful building. Among these factors is the type of material used to construct a building. The qualities of these materials determine how efficient a building is in terms of structure and support. Insulation is a critical property in assessing efficiency of a building material. The ability of a material to act as a good insulator decreases the flow of energy (heat) out of or into the building which is crucial during the summer and winter months (Ezema, 2019). By enhancing the thermal performance of a building, less energy is lost, and the cost of heating and cooling are also reduced (energy.gov, n.d.).

\section{MATHEMATICAL DESCRIPTION AND SOLUTION APPROACH}

The rate of heat loss is theoretically calculated based on two properties: thermal conductance and thermal resistance. For each material, temperature on one side is set to $75^{\circ} \mathrm{F}$ and on the other side, it is set to $100^{\circ} \mathrm{F}$. This is to simulate temperatures inside and outside a building. Each of the materials have a height and width of $5 \mathrm{ft}$ and a thickness of 2 inches. 


\section{$\underline{\text { Rate of heat conduction }}$}

Conduction is the transfer of heat from one substance to the other based on the molecular motion of the material (Ghasemmi and Shahidian, 2017). The results from calculating thermal conductance show the rate at which heat is exiting a system, in this case, a flat material (wood, glass, and brick).

Fourier's Law which describes the rate of heat flow as being proportional to the area of the material and to the negative slope of temperature, is used to assess thermal conductance (Connor, 2019).

Fourier's Law is derived from the heat equation shown below:

$$
\frac{\partial u}{\partial t}=k \frac{\partial^{2} u}{\partial x^{2}}
$$

In partial differential equation (1): $u$ is equal to temperature, $t$ is equal to time, $k$ is a constant (the thermal conductivity of the material), and $x$ is the thickness (Hancock, 2006).

Simplification of equation (1), gives the following equation (Fourier's Law):

$$
Q=-k \Delta T
$$

In (2): $\mathrm{Q}$ is heat flow $\left(\frac{W}{m^{2}}\right), k$ is the thermal conductivity of the material $\left(\frac{W}{m * K}\right)$, and $\Delta T$ is the temperature gradient $\left(\frac{K}{m}\right)$ (Connor, 2019).

Fourier's Law of thermal conductance can be re-written in differential form as follows:

$$
\Delta Q=-k A \frac{d t}{d x}
$$

In (3): $\Delta Q$ is the rate of heat conduction $(\mathrm{W}), k$ is the thermal conductivity value $\left(\frac{W}{m * K}\right)$ of the material; $A$ is the area of the surface $\left(\mathrm{m}^{2}\right)$ and $\frac{d t}{d x}$ is the temperature gradient $\left(\frac{K}{m}\right)$ (Ghasemmi and 
Shahidian, 2017). Thermal conductivity (k) is negative because Fourier's Law states that heat always flows from areas with higher temperatures to areas with lower temperatures, so the negative sign in equation above makes the rate of heat loss positive (Connor, 2019).

This law can be rearranged into the following equation in order to include heat loss through a material with a thickness, $d$ :

$$
\Delta Q=\frac{d Q}{d t}=k A \frac{(T f-T i)}{d}
$$

In (4): $\frac{d Q}{d t}$ is the change in heat flow over the change in time, $T f-T i$ is the change in temperature (outside temperature - indoor temperature) $(K)$, and $d$ is the thickness of the material (m); the thermal conductivity value $k\left(\frac{W}{m * K}\right)$ of the material being tested and the area of the surface $A\left(\mathrm{~m}^{2}\right)$ are the same as in equation (3) (Kosky et. Al, 2012).

Thinking about the rate of heat loss as an integral provides further insight into the problem. An integral can be used to find the area under the curve. For this problem, the theoretical "area under the curve" is the rate at which heat is being lost in the system. The basic integral formula is shown below:

$$
\text { Area }=\int_{a}^{b} f(x) d x
$$

By applying this idea to our equation for heat loss, the following equation is derived:

$$
\Delta Q=k A \int \frac{d T}{d x}
$$

A visual representation of what is occurring in this problem is provided below: 


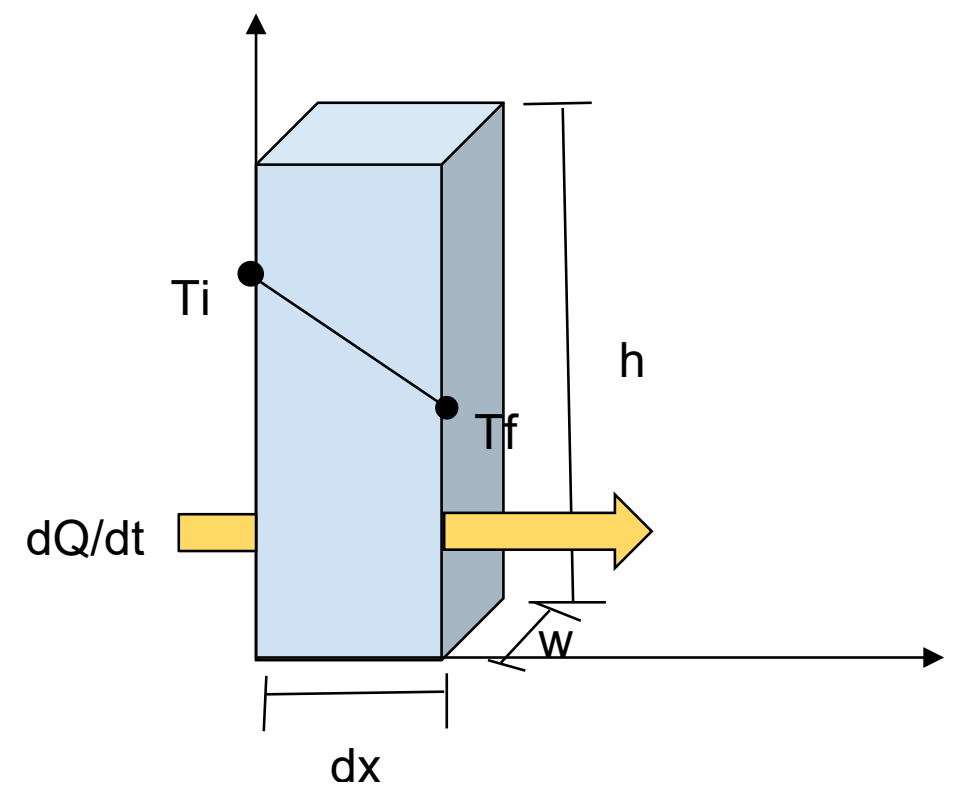

Figure 1: Displays the heat flow across a slab of material. Ti and Tf are the initial and final temperatures, $\frac{d Q}{d t}$ is the rate of heat flow, $\mathrm{dx}$ is the change in thickness, $\mathrm{h}$ is the height, and $\mathrm{w}$ is the width.

Using the equation for thermal conductance (equation 4), the rate of heat loss is calculated when the initial temperature is $75^{\circ} \mathrm{F}$ and the final temperature is $100^{\circ} \mathrm{F}$. The dimensions of each block are $5 \mathrm{ft}$ by $5 \mathrm{ft}$ by 2 inches.

\section{Thermal Resistance}

Thermal resistance is the reciprocal of thermal conductance and shows how well a material is able to resist heat flow. Mathematically, thermal resistance is expressed as a ratio of the temperature gradient and the rate of heat loss (Mishra, 2019).

Starting with the equation for thermal conductance, this equation can be rearranged to solve for resistance instead of conductance. This is shown below:

$$
\begin{gathered}
\Delta Q=k A \frac{T f-T i}{L} \\
R=\frac{L}{k A}
\end{gathered}
$$


The final equation derived solves for thermal resistance $(R)$ and depends only on the thickness of the material $(L)$, thermal conductivity $(k)$, and area of the material $(A)$.

\section{DISCUSSION}

\section{Rate of heat conduction}

The results show that rate of heat conduction is $1719.7 \mathrm{~W}$ (equation 9) for the glass block, 1322.9W (equation 10) for brick, and 88.2 W (equation 11) for the wooden block. Among the three, glass block has the highest rate of heat loss, followed by brick and wooden blocks.

\section{Thermal Resistance}

The results from thermal resistance calculations show that glass has a thermal resistance

(TR) value of $0.0080 \frac{K}{W}$ (equation 12), brick has a TR value of $0.0105 \frac{K}{W}$ (equation 13), and wood has a TR value of $0.157 \frac{K}{W}$ (equation 14). The thermal resistance values suggest that, among the three materials, glass has the lowest ability to resist heat, followed by brick and wood.

Overall, the results imply that glass relative to brick and wood is a poor insulator and is unsuitable for use in buildings that require good insulation such as those in extremely cold or hot environment. Moreover, brick is also not a good insulator and therefore is not suitable for buildings that require a high degree of insulation. Among the three materials, wood was found to be the best insulator with the lowest thermal conductance and the highest thermal resistance values.

The calculations show that higher the thermal conductivity $(k)$ value, higher the rate of heat loss that is occurring, and higher the thermal resistance value $(R)$, lower the rate of heat loss that is occurring. 


\section{CONCLUSION AND RECOMMENDATIONS}

Our results show which material has the highest rate of heat loss and therefore is the poorest insulator of heat. Compared to wood, brick and glass are poor insulators of heat.

Other factors could be tested such as the thickness of the material or how one or more of these materials combined affect the thermal conductance and thermal resistance of a building. Adding other insulating materials such as fiberglass or mineral wool would also affect the degree to which a building is insulated against heat. Since there are several factors that affect insulation of a building, decisions about materials used for construction cannot be based on this study alone, but on a combination of various studies pertaining to the rate of heat flow of materials.

NOMENCLATURE

\begin{tabular}{|c|c|}
\hline Name & Units \\
\hline Watts & $\mathrm{W}$ \\
\hline Meters & $\mathrm{m}$ \\
\hline Meters-squared & $\mathrm{m}^{2}$ \\
\hline Kelvin & $\mathrm{K}$ \\
\hline Degrees Celsius & ${ }^{\circ} \mathrm{C}$ \\
\hline Degrees Fahrenheit & ${ }^{\circ} \mathrm{F}$ \\
\hline
\end{tabular}




\section{REFERENCES}

Insulation Materials. (n.d.). Retrieved from

https://www.energy.gov/energysaver/weatherize/insulation/insulation-materials

Heat conduction. (n.d.). Retrieved from https://www.newworldencyclopedia.org/entry/Heat_conduction

Alam, T. (n.d.). Tahsina Alam. Retrieved from https://civiltoday.com/civil-engineering-materials/brick/157-thermal-conductivity-ofbrick

Lampinen, M., Assad, M. el H., \& Curd, E. F. (2001). 4 - Physical fundamentals. Industrial Ventilation Design Guidebook, 41-171. https://doiorg.ezproxy.lib.usf.edu/10.1016/B978-012289676-7/50007-2

Ghassemi, M., \& Shahidian, A. (2017, March 24). Chapter 3- Biosystems Heat and Mass Transfer. Retrieved April 27, 2020, from https://doi.org/10.1016/B978-0-12-8037799.00003-0

Kosky, P., Balmer, R., Keat, W., \& Wise, G. (2012, June 29). Chapter 12 - Mechanical Engineering. Retrieved April 27, 2020, from https://doi.org/10.1016/B978-0-12-4158917.00012-1

Gellert, R. (2014, March 27). 8 - Inorganic mineral materials for insulation in buildings. Retrieved April 27, 2020, from https://doi.org/10.1533/9781845699277.2.193

Ashby, M. F., Ferreira, P. J., \& Schodek, D. L. (2009, April 22). Chapter 9 - Design Environments and Systems. Retrieved April 27, 2020, from https://doi.org/10.1016/B978-0-7506-8149-0.00011-8

Mishra, R., Militky, J., \& Venkataraman, M. (2019, January 11). 7 - Nanoporous materials. Retrieved April 27, 2020, from https://doi.org/10.1016/B978-0-08-102609-0.00007-9

Thermal Resistance - Thermal Resistivity. (n.d.). Retrieved from https://www.nuclear-power.net/nuclear-engineering/heat-transfer/thermalconduction/thermal-resistance-thermal-resistivity/

(n.d.). Retrieved from http://hyperphysics.phy-astr.gsu.edu/hbase/Tables/thren.html

Ezema, I. (2019, January 11). Chapter 9 - Materials. Retrieved April 27, 2020, from https://doi.org/10.1016/B978-0-12-811749-1.00007-9

Bourne, M. (n.d.). 2. Area Under a Curve by Integration. Retrieved from https://www.intmath.com/applications-integration/2-area-under-curve.php

(n.d.). Retrieved from https://cnx.org/contents/nEURLMwu@1.140:6EiQTxeh@14/Mechanisms-of-HeatTransfer

Hancock, M. J. (2006). The 1-D Heat Equation 18.303 Linear Partial Differential Equations. Retrieved from https://ocw.mit.edu/courses/mathematics/18-303-linear-partialdifferential-equations-fall-2006/lecture-notes/heateqni.pdf

Connor, N. (2019, June 4). What is Fourier's Law of Thermal Conduction - Definition. Retrieved from https://www.thermal-engineering.org/what-is-fouriers-law-of-thermal-conductiondefinition/ 


\section{APPENDICES}

\section{Equations}

$$
\begin{aligned}
& \frac{\partial u}{\partial t}=k \frac{\partial^{2} u}{\partial x^{2}} \\
& Q=-k \Delta T \\
& \Delta Q=-k A \frac{d t}{d x} \\
& \Delta Q=\frac{d Q}{d t}=k A \frac{(T f-T i)}{d} \\
& \text { Area }=\int_{a}^{b} f(x) d x \\
& \Delta Q=k A \int \frac{d T}{d x} \\
& \Delta Q=k A \frac{T f-T i}{L} \\
& R=\frac{L}{k A}
\end{aligned}
$$

\section{$\underline{\text { Calculations }}$}

\section{Units Conversion for Temperature}

Fahrenheit to Kelvin

$\mathrm{Tf}=100^{\circ} \mathrm{F}$

${ }^{\circ} \mathrm{F}$ to $\mathrm{K}=\left(100^{\circ} \mathrm{F}+459.67\right) * \frac{5}{9}=310.928 \mathrm{~K}$

$\mathrm{Ti}=75^{\circ} \mathrm{F}$

${ }^{\circ} \mathrm{F}$ to $\mathrm{K}=\left(75^{\circ} \mathrm{F}+459.67\right) * \frac{5}{9}=297.039 \mathrm{~K}$

\section{Units Conversion for Area}

$\mathrm{A}=5 f t * 5 f t=25 f t^{2}$

$25 f t^{2}=7.62 m^{2}$

\section{Units Conversion for Thickness}

$$
\begin{aligned}
& d=2 \text { in }=0.16 f t \\
& 0.16 f t=0.048 m
\end{aligned}
$$


Calculations of the rate of heat conduction

\section{Glass}

$\Delta Q=k A \frac{(T f-T i)}{d}$

$\Delta Q=\left(0.78 \frac{W}{m * K}\right)\left(7.62 m^{2}\right) \frac{(310.928-297.039 \mathrm{~K})}{0.048 \mathrm{~m}}=1719.7 \mathrm{~W}$

\section{Brick}

$\Delta Q=k A \frac{(T f-T i)}{d}$

$\Delta Q=\left(0.6 \frac{W}{m * K}\right)\left(7.62 m^{2}\right) \frac{(310.928-297.039 \mathrm{~K})}{0.048 \mathrm{~m}}=1322.9 \mathrm{~W}$

\section{Wood}

$\Delta Q=k A \frac{(T f-T i)}{d}$

$\Delta Q=\left(0.04 \frac{W}{m * K}\right)\left(7.62 m^{2}\right) \frac{(310.928-297.039 \mathrm{~K})}{0.048 \mathrm{~m}}=88.2 \mathrm{~W}$

Thermal Resistance:

\section{Glass}

$$
\begin{aligned}
& R=\frac{L}{k A} \\
& R=\frac{0.048 m}{\left(0.78 \frac{W}{m * K}\right)\left(7.62 m^{2}\right)}=0.0080 \frac{K}{W}
\end{aligned}
$$

\section{Brick}




$$
\begin{aligned}
& R=\frac{L}{k A} \\
& R=\frac{0.048 \mathrm{~m}}{\left(0.6 \frac{W}{m * K}\right)\left(7.62 \mathrm{~m}^{2}\right)}=0.0105 \frac{K}{W}
\end{aligned}
$$

\section{Wood}

$R=\frac{L}{k A}$

$R=\frac{0.048 m}{\left(0.04 \frac{W}{m * K}\right)\left(7.62 m^{2}\right)}=0.157 \frac{K}{W}$

\section{Thermal Conductivity for All Three Materials}

\begin{tabular}{|l|l|}
\hline Material & Thermal Conductivity, $\mathrm{k}\left(\frac{W}{m * K}\right)$ \\
\hline Glass & 0.78 \\
\hline Brick & 0.6 \\
\hline Wood & 0.04 \\
\hline
\end{tabular}

Figure 2: This table displays the thermal conductivities for the three materials tested. 